\title{
Recent developments in reactivity testing of supplementary cementitious materials
}

\author{
Prannoy Suraneni ${ }^{10 *}$ \\ ${ }^{1}$ Department of Civil and Architectural Engineering, University of Miami, Coral Gables, FL 33416, USA \\ ${ }^{\circ}$ Prannoy Suraneni was invited for submission of this letter as an awardee of the Gustavo Colonnetti Medal granted by RILEM in 2021
}

Received: 05 November 2021 / Accepted: 09 December 2021 / Published online: 29 December 2021

(C) The Author(s) 2021. This article is published with open access and licensed under a Creative Commons Attribution 4.0 International License.

\begin{abstract}
Identification and rapid characterization of novel supplementary cementitious materials (SCMs) is a critical need, driven by shortfalls in conventional SCMs. In this study, we present a discussion of recently developed reactivity tests - the $\mathrm{R}^{3}$ test, the modified $\mathrm{R}^{3}$ test, the lime strength test, and the bulk resistivity index test. These tests measure reactivity parameters such as heat release, bound water, calcium hydroxide consumption, strength, and bulk resistivity. All tests can screen inert from reactive materials. To additionally differentiate pozzolanic and latent hydraulic materials, two parameters, for example, calcium hydroxide consumption and heat release, are typically needed. The influences of SCM bulk chemistry, amorphous content, and fineness on measured reactivity are outlined. Reactivity test outputs can predict strength and durability of cement paste/mortar/concrete; however, caution must be exercised as these properties are influenced by a variety of other factors independent of reactivity. Thoughts are provided on using reactivity tests to screen materials for concrete durability.
\end{abstract}

Keywords: Reactivity; Supplementary cementitious materials; Durability; Calcium hydroxide; Heat release; Bulk resistivity

\section{Introduction}

Currently, more than 5 billion tons of cement and 15 billion tons of concrete are produced annually $[1,2]$ and substantial increases in these numbers are anticipated over the next 30 years [1]. Cement production accounts for $6 \%$ of total anthropogenic greenhouse gas emissions [1] due to process fuel combustion and limestone decomposition. As we must reduce global $\mathrm{CO}_{2}$ emissions, $\mathrm{CO}_{2}$ emissions from cement must be reduced. Mitigation strategies are covered at length in $[1,2]$. At this time, the use of low-carbon supplementary cementitious materials (SCMs) to replace cement, is one of the most promising strategies to reduce cement $\mathrm{CO}_{2}$ emissions [1].

SCMs have long been used in concrete for the benefits they provide to concrete durability [3]. Classical SCMs such as fly ash and slag improve concrete durability, including for alkalisilica reaction (ASR) and sulfate attack, due to their pozzolanic and/or latent hydraulic reactions [3-5]. Due to changing industrialization trends like the near-global shutdown of coalfired power plants, the availability of fly ash and slag has considerably reduced. Therefore, there is a critical need to identify, characterize, and ultimately use alternative SCMs [3]. Fig. 1 shows the availability (million tons/year) of cement and several SCMs. The materials which have the greatest global potential to reduce cement $\mathrm{CO}_{2}$ emissions are limestone, fillers, tailings, calcined clays, natural pozzolans, and alternative fly ashes.

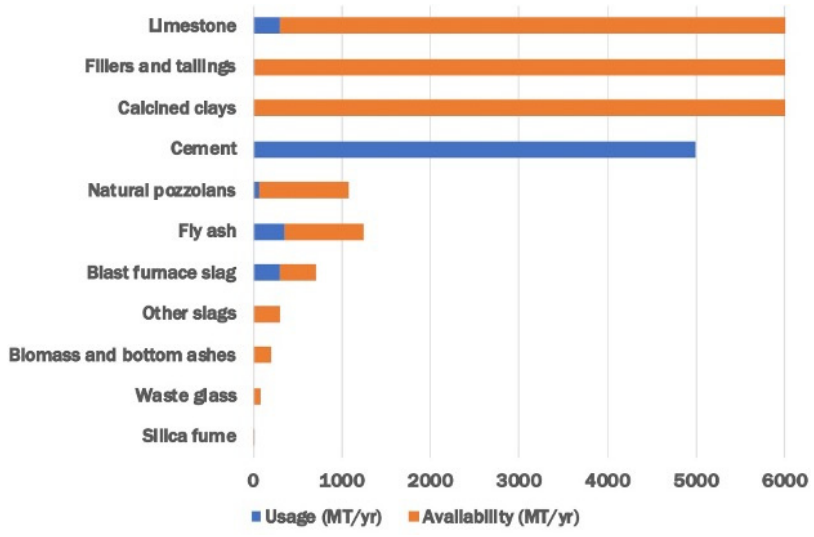

Figure 1. Availability of cement, conventional SCMs, and alternative SCMs (adapted from [1]).

Considerable research has been carried out on a variety of alternative SCMs $[3,6-8]$. Because the number of available sources is large, there is significant merit in providing the ability to rapidly determine whether a material is an SCM or not. Here, we differentiate pozzolanic and latent hydraulic SCMs from inert fillers such as limestone [9]. While it is important to use inert fillers in concrete, and they can

\footnotetext{
* Corresponding author: Prannoy Suraneni, E-mail: suranenip@miami.edu
} 
improve concrete properties due to filler effect and reactions with aluminate phases, they do not show pozzolanic/latent hydraulic reactions [10]. Their extent of reaction, and consequently, allowable replacement level in concrete are both low [10]. For a material to be a feasible SCM, its reactivity is one of, if not the most important factors $[8,10]$. Microstructural refinement, which is the cause of long-term improvement in properties of concrete with SCMs is largely a consequence of SCM reaction $[3,11]$. Therefore, in order to consistently use alternative SCMs in concrete, their reactivity (extent and type of reaction) must be understood.

The number of tests that can be used to quantify SCM reactivity directly or indirectly is substantial. Older tests such as the strength activity index test, Chapelle test, Frattini test, etc. are not always successful in screening inert and reactive materials, and some of them are inapplicable for latent hydraulic materials. A discussion of these tests, including their flaws, is presented in [12] but they are not covered in this work. The scope of this work is limited to four recently developed reactivity tests - the $R^{3}$ test [13], the modified $R^{3}$ test [9], the lime strength test [14], and the bulk resistivity index test [15]. The ability of the tests to differentiate inert, pozzolanic, and latent hydraulic materials is assessed. Links between reactivity and SCM chemistry and fineness are uncovered. The ability of SCM reactivity to predict strength and durability of concrete containing SCMs is highlighted, with one objective being rapid screening of materials for durability.

\section{Overview of Reactivity Tests}

An overview of the different reactivity tests is shown in Table 1.

\subsection{The $\mathrm{R}^{3}$ test}

The $R^{3}$ test involves the measurement of heat release or bound water in a SCM-calcium hydroxide model system cured at $40{ }^{\circ} \mathrm{C}$ for 7 days [13]. The test has been standardized as ASTM C1897 and is being increasingly used, including in industry, because of the ease of running bound water measurements. The test differentiates inert and reactive SCMs, and differentiation between pozzolanic and latent hydraulic materials could be achieved by using an additional measure of calcium hydroxide consumption [16]. Heat release and bound water correlate to each other and to the 28-day strength in mortars with $30 \%$ SCM mass replacement $[8,13]$.

\subsection{The modified $\mathrm{R}^{3}$ test}

The modified $\mathrm{R}^{3}$ test involves the measurement of heat release and calcium hydroxide consumption in a SCM-calcium hydroxide model system cured at $50{ }^{\circ} \mathrm{C}$ for 10 days. The mixture design is similar to that in the $\mathrm{R}^{3}$ test, but without additional sulfates and carbonates $[9,17]$. Removing sulfates and carbonates simplifies the system; this was done in part because their exact roles in real systems are complex and system dependant. Because of the longer duration and higher temperature, this test has greater acceleration and is more reflective of later-age properties than the $R^{3}$ test [13], an important consideration for slowly reacting materials such as Class $\mathrm{F}$ fly ashes. By using both heat release and calcium hydroxide consumption, this test differentiates inert, pozzolanic, and latent hydraulic materials. Classification schemes based on type and extent of reactivity were proposed $[9,17]$.

\subsection{The lime strength test}

In this test, the compressive strength of a lime mortar is measured $[14,18]$. This test is based on the modification of the Canadian test method (CSA A3004-E1) through optimization of mixture proportions, mixing solution, curing solution, and curing temperature as detailed in [14]. The test can differentiate inert and reactive materials and classification of materials ranging from inert to very high reactivity has been proposed [18]. The 91-day concrete compressive strength and bulk resistivity were moderately correlated to the 7-day lime (mortar) strengths [18].

Table 1. Overview of mixture design, curing, properties measured, reactivity thresholds, and classification in different reactivity tests [8,9,14-18]. The notations used are: $\mathrm{l} / \mathrm{s}$ - liquid/solid, w/b - water/binder, and s/b - sand/binder, $\mathrm{CH}$ - calcium hydroxide. All ratios are by mass.

\begin{tabular}{|c|c|c|c|c|}
\hline Test & $\mathbf{R}^{3}$ test & Modified $\mathrm{R}^{3}$ test & Lime strength test & Bulk resistivity index test \\
\hline $\begin{array}{l}\text { Mixture } \\
\text { design }\end{array}$ & $\begin{array}{l}\mathrm{SCM} 11.11 \mathrm{~g}, \mathrm{CH} 33.33 \mathrm{~g}, \\
\text { water } 60.00 \mathrm{~g}, \mathrm{KOH} 0.24 \mathrm{~g}, \\
\mathrm{~K}_{2} \mathrm{SO}_{4} 1.20 \mathrm{~g}_{,} \mathrm{CaCO}_{3} 5.56 \mathrm{~g}\end{array}$ & $\begin{array}{l}\text { SCM: } \mathrm{CH} 1: 3, \mathrm{l} / \mathrm{s} 0.9 \text {, } \\
\text { liquid is } 0.5 \mathrm{M} \mathrm{KOH} \\
\text { solution }\end{array}$ & $\begin{array}{l}\mathrm{CH}: \mathrm{SCM} 1: 1.5, \mathrm{w} / \mathrm{b} 0.65, \mathrm{~s} / \mathrm{b} 2.5, \\
\mathrm{CaCO}_{3} /\left(\mathrm{SCM}+\mathrm{CH}+\mathrm{CaCO}_{3}\right) 1: 15 ; \\
\mathrm{K}_{2} \mathrm{SO} 4 / \mathrm{KOH}=5 \text { and } 0.3 \mathrm{M} \mathrm{K}^{+} \text {solution }\end{array}$ & $\begin{array}{l}\text { SCM replacements of } 30 \% \\
\text { or } 50 \% \text { by mass, w/b } 0.40 \text {, } \\
\text { s/b } 2.75\end{array}$ \\
\hline $\begin{array}{l}\text { Curing } \\
\text { conditions }\end{array}$ & $\begin{array}{l}40{ }^{\circ} \mathrm{C} \text { for } 7 \text { days in sealed } \\
\text { conditions }\end{array}$ & $\begin{array}{l}50{ }^{\circ} \mathrm{C} \text { for } 10 \text { days in } \\
\text { sealed conditions }\end{array}$ & $\begin{array}{l}\text { Mortars stored over water at } 23^{\circ} \mathrm{C} \\
\text { ( } 1 \text { day), in an oven at } 40{ }^{\circ} \mathrm{C}(2 \text { days }), \\
\text { and then in water at } 40^{\circ} \mathrm{C} \text { ( } 4 \text { days) }\end{array}$ & $\begin{array}{l}\text { Mortars cured at } 23{ }^{\circ} \mathrm{C} \text { in } \\
\text { moist room ( } 1 \text { day), then at } \\
50{ }^{\circ} \mathrm{C} \text { in limewater ( } 6 \text { days) }\end{array}$ \\
\hline $\begin{array}{l}\text { Properties } \\
\text { measured }\end{array}$ & $\begin{array}{l}\text { Heat release and/or } \\
\text { bound water }\end{array}$ & $\begin{array}{l}\text { Heat release (or bound } \\
\text { water) and } \mathrm{CH} \\
\text { consumption }\end{array}$ & Compressive strength & $\begin{array}{l}\text { Bulk resistivity (normalized } \\
\text { to control with no SCMs) }\end{array}$ \\
\hline $\begin{array}{l}\text { Reactivity } \\
\text { threshold }\end{array}$ & $\begin{array}{l}\text { 7-day heat release } 100 \mathrm{~J} / \mathrm{g} \\
\mathrm{SCM} \text {, bound water } 4 \%\end{array}$ & $\begin{array}{l}\text { 10-day heat release } \\
120 \mathrm{~J} / \mathrm{g} \mathrm{SCM}, \mathrm{CH} \\
\text { consumption } 50 \mathrm{~g} / 100 \\
\text { g SCM }\end{array}$ & 7-day strength $3 \mathrm{MPa}$ & $\begin{array}{l}100 \% \text { bulk resistivity of } \\
\text { control mortar }\end{array}$ \\
\hline Classification & Not proposed & $\begin{array}{l}\text { Classification using } \\
\text { heat release and } \mathrm{CH} \\
\text { consumption }\end{array}$ & $\begin{array}{l}\text { Classes from inert to very high } \\
\text { reactivity proposed }\end{array}$ & Not proposed \\
\hline
\end{tabular}




\subsection{Bulk resistivity index test}

Several studies have shown that bulk resistivity is able to differentiate between inert and reactive materials, as the latter show increased values of bulk resistivity, especially at later ages, higher temperatures, and greater SCM mass replacements $[15,18,19]$. The bulk resistivity index test involves the non-destructive measurement of bulk resistivity at 7 and 28 days, the value of which is normalized using the corresponding bulk resistivity of the control mortar (no SCM). The test can differentiate between inert and reactive materials [15].

\subsection{Comparison between various tests}

Table 1 shows the reactivity thresholds and classification schemes of the different reactivity tests; the thresholds continue to evolve as test development has progressed and further novel materials are evaluated. Heat release, bound water, calcium hydroxide consumption, or strength measured in these tests have been correlated to various cement paste, mortar, or concrete properties. Reactivity increases as the value of the measured property increases and all tests are able to differentiate between inert and reactive materials [8-20].

Because they are performed on mortar mixtures, and involve the measurement of familiar properties, it could be argued that the lime strength and bulk resistivity index tests are simpler than the $R^{3}$ or modified $R^{3}$ test. The modified $R^{3}$ test is the most complex of these tests because of the need for isothermal calorimetry and thermogravimetric analysis to measure heat release and calcium hydroxide consumption, respectively. Unpublished work from our group has suggested that a furnace could be used to measure both bound water and calcium hydroxide consumption, which would reduce the cost and simplify the modified $R^{3}$ test. The mixture designs for these tests are a result of rigorous testing, although further optimization could be possible after ruggedness and round robin testing. To the authors knowledge, these last steps have only been completed for the $\mathrm{R}^{3}$ test (ASTM C1897).

It is noted that the $\mathrm{R}^{3}$ test is benchmarked and shows strong correlations with the 28-day mortar strength [13]. The modified $\mathrm{R}^{3}$ test measures both heat release and calcium hydroxide consumption. While correlations with later-age concrete strength have been demonstrated [20], this test is not aimed to estimate strength. Considering the numerous factors that affect strength, the variability of strength, and the issues with strength measures such as the strength activity index [15], it is the opinion of the author that reactivity tests do not have to be able to estimate strength. Mortar compressive strength and bulk resistivity index do not correlate, as resistivity is far more sensitive to reactivity than strength [15]. In the bulk resistivity index test, Class F fly ashes show greater bulk resistivity than Class $C$ fly ashes, while the reverse is generally true for strength [15].

The curing conditions in the different tests vary, as some use $40{ }^{\circ} \mathrm{C}$ whereas others use $50{ }^{\circ} \mathrm{C}$. The choice of temperature does not matter if the objective is to screen inert from reactive materials. However, if the objective is to quantify reactivity or to link reactivity to concrete properties, then the choice of temperature is more important. Using a lower temperature is advantageous in terms of phase stability and generation of realistic hydration products. In addition, at 50 ${ }^{\circ} \mathrm{C}$, quartz and other inert materials show greater extent of reactions than at $40^{\circ} \mathrm{C}$ or at room temperature [9]. However, the lower temperature may not be adequate for low reactive/slowly reacting materials [13]. Fig. 2 shows the heat release that we measured for ten unconventional fly ashes using both the $R^{3}$ and the modified $R^{3}$ tests, arranged in increasing order of heat release from the $R^{3}$ test. F1 to $F 5$ are Class F fly ashes and C1 to C5 are Class C fly ashes. In the $\mathrm{R}^{3}$ test, Class C fly ashes (387 J/g SCM) show a substantially greater heat release than the Class F fly ashes (163 J/g SCM). This is not the case in the modified $R^{3}$ test, with the values being $301 \mathrm{~J} / \mathrm{g}$ and $270 \mathrm{~J} / \mathrm{g}$ for Class C and Class F fly ashes, respectively. This difference is important, as Class $C$ fly ashes are more reactive than Class $\mathrm{F}$ fly ashes in cement pastes at 28 days, but not necessarily at 91 days [21]. The slow but sustained reactivity of the Class F fly ashes is not fully captured in the $\mathrm{R}^{3}$ test, but it is better captured in the modified $\mathrm{R}^{3}$ test. It is well known that Class F fly ashes outperform Class C fly ashes in most measures of durability - for example, ASR. Thus, the higher temperature curing may be a better choice if durability assessments are to be made from reactivity tests, especially for slowly reacting materials. A more holistic picture of material reactivity could be obtained by measuring reactivity at both $40{ }^{\circ} \mathrm{C}$ and $50{ }^{\circ} \mathrm{C}$. Alternatively, kinetic corrections or data extrapolation/fitting could be used to estimate long-term reactivity of slowly reacting materials at $40^{\circ} \mathrm{C}$.

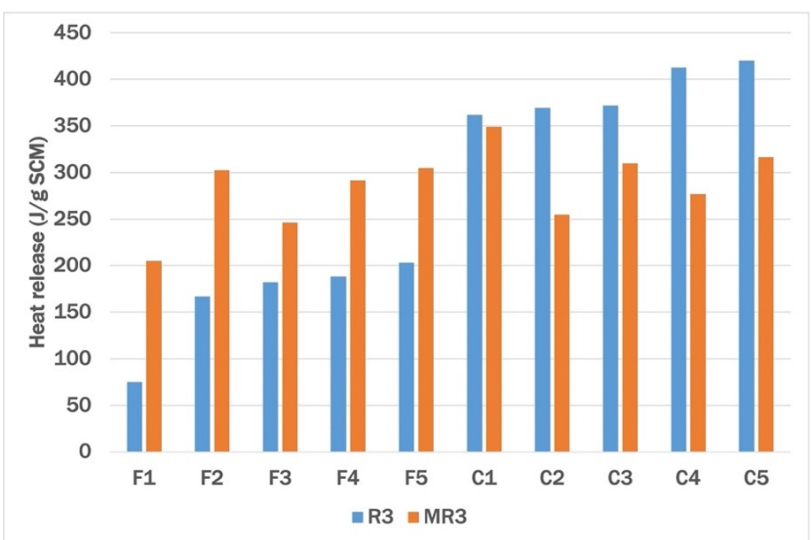

Figure 2. Heat release of unconventional fly ashes using the $R^{3}$ and modified $\mathrm{R}^{3}$ tests (unpublished data).

\subsection{Are two measures of reactivity required?}

Fig. 3 shows the strong correlation between heat release and calcium hydroxide consumption for several SCMs (excluding slag) using the modified $\mathrm{R}^{3}$ test [9]. All reactive SCMs except the latent hydraulic slags provide a heat release/calcium hydroxide consumption ratio of around 4. The exact relationship between these two parameters depends on SCM chemistry [9], which is unsurprising because of differences in reactions that happen with siliceous or aluminosilicate 
materials. The argument for obtaining two measurements of reactivity has been that two measures are needed to differentiate latent hydraulic and pozzolanic materials. While this is technically true, if the purpose of reactivity testing is screening, the differentiation could be done on the basis of chemical composition - latent hydraulic materials such as slag have bulk $\mathrm{CaO}$ contents greater than $20 \%$ [9]. For materials with $\mathrm{CaO}>20 \%$, it could be useful to measure both heat release and calcium hydroxide consumption. For materials with $\mathrm{CaO}<20 \%$, one of these parameters could be used to estimate the others using the relationship in Fig. 3 or approaches discussed in [9]. If, however, reactivity testing is intended to estimate durability behavior, these approaches may lead to unacceptable errors due to the scatter evident in Fig. 3. Correlations between heat release and calcium hydroxide consumption in the $\mathrm{R}^{3}$ test have also been demonstrated [22]. Procedural modifications which improve the correlation, including carbonation, thermogravimetry of the original SCMs, and drying corrections were proposed.

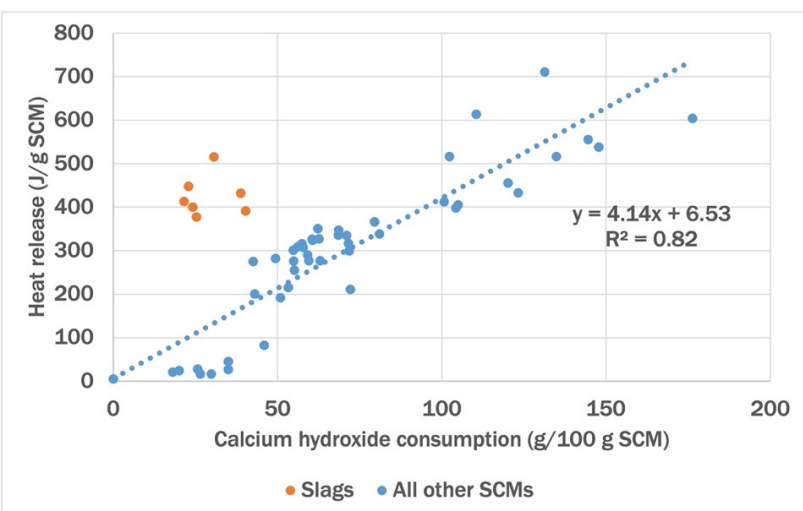

Figure 3. Heat release plotted against calcium hydroxide consumption for several SCMs of different types using the modified $\mathrm{R}^{3}$ test (adapted using data from [9]).

\section{Influences of SCM properties on reactivity}

\subsection{Bulk chemistry and amorphous content}

The influences of SCM bulk chemistry on reactivity have been investigated for a single type of SCM and across SCM types. Behavioral differences between highly reactive silica fume and inert quartz sand, both of which have similar bulk chemistry (around $90 \% \mathrm{SiO}_{2}$ ), show that reactivity and bulk chemistry links should be cautiously interpreted. It is the amorphous content and phases in most SCMs that drive reactivity and not the bulk chemistry, explaining the limited utility of bulk chemistry-reactivity relationships. Regardless, our data has revealed several interesting relationships between reactivity and bulk chemistry, with an example shown in Fig. 4. Calcium hydroxide consumption increases with bulk $\mathrm{Al}_{2} \mathrm{O}_{3}$ content when the latter is greater than $15 \%$. The scatter at low bulk $\mathrm{Al}_{2} \mathrm{O}_{3}$ content is caused by differences in reactivity of materials such as quartz and silica fume, which have similar bulk $\mathrm{Al}_{2} \mathrm{O}_{3}$ contents [9].

Direct correlations between reactivity and SCM amorphous content do not seem to be present in literature, likely because of the challenges associated with systematically varying amorphous contents and the influences of glass chemistry and fineness. Recent publications have uncovered the impact of composition on the reactivity of synthetic calcium aluminosilicate glasses using tests similar to the $\mathrm{R}^{3}$ test $[23,24]$. Similar trends in dissolution and reactivity were discovered; both increased as the glass network depolymerized [23]. Glass reactivity increased as $\mathrm{CaO}$ and/or $\mathrm{Al}_{2} \mathrm{O}_{3}$ contents increased [23], with the former acting by depolymerizing the glass network and the latter by chemical weakening of the glass structure [24]. Reactivity testing of magnesium substituted calcium aluminosilicate glasses confirm that glass reactivity is to a large extent governed by glass network depolymerization [25]. Network modifiers can destabilize the glass in slag systems, and thus increase dissolution and reactivity [26]. Impacts of glass composition on SCM reaction kinetics appear not to have been investigated in detail.

When limited to one type of SCMs; specifically calcined clays, the kaolinite content controls their reactivity; the heat release measured in the $\mathrm{R}^{3}$ test increases linearly as the kaolinite content increases $[8,27]$. Calcined kaolinite systems are substantially more reactive than calcined montmorillonite or illite systems due to their greater disorder and the presence of 5-coordinated aluminum [28].

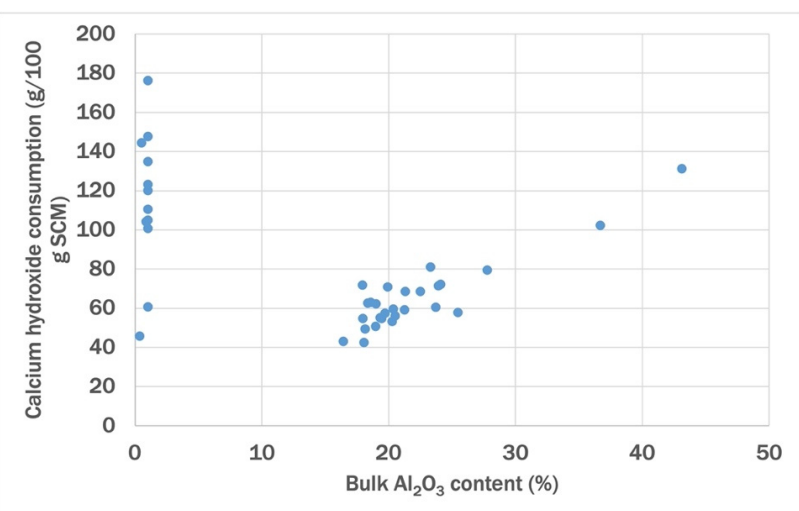

Figure 4. Calcium hydroxide consumption using the modified $\mathrm{R}^{3}$ test plotted against bulk $\mathrm{Al}_{2} \mathrm{O}_{3}$ content for several SCMs of different types (using data from [9]).

\subsection{SCM fineness}

Using the same slag milled to six different fineness levels and a protocol similar to the $\mathrm{R}^{3}$ test, Blotevogel et al. showed a linear increase of the heat release as specific surface area increased [29]. The 1-day heat release increased by about 4 $\mathrm{J} / \mathrm{g}$ for a $10 \mathrm{~m}^{2} / \mathrm{kg}$ increase in surface area. At all ages, the $\mathrm{R}^{3}$ test heat release increased as the fineness increased for a non-ferrous metallurgy slag [30].

A summary of results from our lab showing the effects of fineness on reactivity is illustrated in Fig. 5. When mine tailings were milled using a high-energy disc mill, their fineness, amorphous content, and reactivity quantified using the modified $R^{3}$ test, all increased with the milling duration [31]. Because of varying fineness and amorphous contents, reactivity did not show a linear relationship with either, but increased significantly beyond certain thresholds of both parameters, in what can be considered activation of these 
low-reactivity materials. The reactivity of commercially available pumice and glass powder, measured by heat release and calcium hydroxide consumption in the modified $\mathrm{R}^{3}$ test, increased as the fineness increased and the median particle size decreased; however, for limestone there was no influence of fineness on reactivity [32]. While reactivity typically increases with fineness, the type of milling and the material being milled affect the relationship between reactivity and fineness. Very coarse SCMs can register as inert in a reactivity test, even if they have intrinsic reactivity, as seen in Fig. 5 for the ground glass with $120 \mu \mathrm{m}$ median particle size, which shows very low reactivity. Fineness effects were also investigated using the lime strength test for raw and ground bottom ash [18]. The raw bottom ash $(730 \mu \mathrm{m}$ median particle size) showed a strength of $0.5 \mathrm{MPa}$ and was classed as inert. On the other hand, the ground bottom ash $(2.4 \mu \mathrm{m}$ median particle size) showed a strength that was 30 times higher at $15 \mathrm{MPa}$ and was classed as high reactivity. In order to eliminate the effects of fineness to compare intrinsic material reactivity, one could compare material reactivity at equal fineness or compare material reactivity at multiple fineness levels and then correct for fineness.

In addition to milling, fineness can also be increased through size classification. Using heat release in the $\mathrm{R}^{3}$ test, 40 to $57 \%$ increase in reactivity was quantified for size-classified or milled Class F fly ash. Phase composition had only a secondary effect on the reactivity [33]. However, this finding may not hold true for some Class C fly ashes. Ongoing studies in our lab using the modified $\mathrm{R}^{3}$ test suggest complex compositional and fineness effects on the reactivity of size fractionated alternative fly ashes. Class F fly ashes did not show substantial compositional changes after size classification, but some Class $\mathrm{C}$ fly ashes showed reduced bulk $\mathrm{CaO}$ contents in their coarse fractions to the extent that the coarse fractions would be categorized as Class F fly ashes.

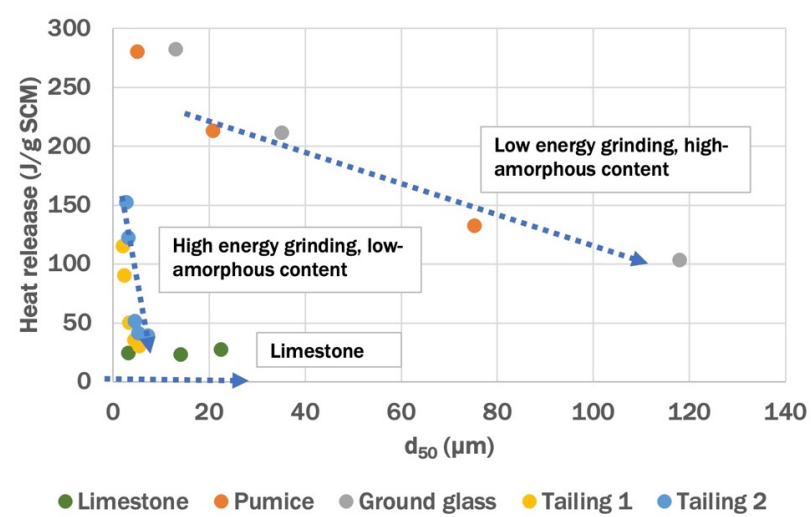

Figure 5. Influence of fineness on heat release using the modified $R^{3}$ test (adapted using data from [31,32]).

\section{Prediction of cement paste, mortar, and concrete properties}

A number of publications have used reactivity test outputs to predict the properties of cement paste, mortar, and concrete, or have discussed the potential of doing so [8-10,12-14,1620,32-35]. We do not attempt to cover all publications or their results in detail, but present important findings and their implications.

\subsection{The $\mathrm{R}^{3}$ test}

The 28-day mortar compressive strength correlates well with the 7-day heat release in the $\mathrm{R}^{3}$ test; correlations with mortar strength at 7-days and 90-days were also explored using 0.5, 1,3 , and 7 day heat release/bound water [13]. The heat release in the $\mathrm{R}^{3}$ test is unable to predict the 90-day mortar strengths as well as it can predict the 7-day or 28-day strengths. These predictive differences are by design and appear to be due to sustained strength gain in the slowly reacting Class F fly ashes [13]. In another study, the 2-day compressive strengths of mortars with $75 \%$ slag were predicted based on slag 1-day heat release in the $R^{3}$ test [29]. In yet another study, strong correlations $\left(R^{2}=0.85\right)$ between 180-day mortar strengths and the 7-day $R^{3}$ bound water were demonstrated, however, the Class $\mathrm{F}$ fly ash showed greater strength than expected from its bound water value [35]. $\mathrm{R}^{3}$ tests have also been used to show correlations between heat release/bound water and strength development in synthetic calcium aluminosilicate glasses [24].

The heat release/bound water is not expected to be an direct indicator of durability behavior, as it is an overall measure of reactivity [36]. High $\mathrm{CaO}$ materials, including Class $\mathrm{C}$ fly ashes and slag typically generate high heat release, however, they perform poorly in ASR testing. For ASR expansion, additional screening/corrections based on $\mathrm{CaO}$ and alkali content are needed. SCM reactivity determined using $\mathrm{R}^{3}$ testing was unable to predict SCM behavior in mitigating sulfate attack expansion. Sulfate resistance results for materials with similar reactivity varied, possibly due to the presence of crystalline or other phases that were reactive but did not suppress sulfate attack expansion [36].

\subsection{The modified $\mathrm{R}^{3}$ test}

Correlations have been discovered between later-age (56 days or greater) calcium hydroxide content and bulk resistivity in cement pastes and the calcium hydroxide consumption in the modified $R^{3}$ test $[32,37]$. Damage occurs in cement pastes and concretes exposed to concentrated calcium chloride solutions and low temperatures due to calcium oxychloride formation. This damage reduces as laterage calcium hydroxide content reduces or as the later-age bulk resistivity increases due to reduction of damage potential and microstructural densification $[38,39]$. In other words, the reactivity in the modified $\mathrm{R}^{3}$ test can predict calcium oxychloride damage. Therefore, SCMs with higher calcium hydroxide consumption in the modified $R^{3}$ test are expected to mitigate concrete calcium oxychloride damage at lower replacement levels than SCMs with lower calcium hydroxide consumption.

Increased later-age bulk resistivity in concrete is driven by microstructural refinement, which is a consequence of sustained SCM reaction [3,11,19]. Across multiple studies and for different SCM types, we have shown that the later-age bulk resistivity is correlated with measures of calcium hydroxide in model systems and cement pastes [10,15,19,32]. 
While formation factor is a more fundamental property, relationships between chloride diffusion coefficients and bulk resistivity have been developed and validated [40], meaning that calcium hydroxide consumption could be used to estimate chloride diffusion coefficients.

Another durability property intimately linked to pozzolanic reaction is ASR expansion/mitigation. As illustrated in Fig. 6, there is a logarithmic relationship between the ASR expansion from the accelerated mortar bar test and the product of the calcium hydroxide consumption in the modified $R^{3}$ test with the mortar SCM replacement. No relationship was found when heat release was used instead of the calcium hydroxide consumption, because the heat release is an indicator of both pozzolanic and latent hydraulic reactions. There are very wellknown limitations of the accelerated mortar bar test; however, this figure can be used to illustrate the ability of reactivity tests to screen for concrete durability. First, we note that for ASR, as for calcium oxychloride damage, SCM replacement plays a major role - these damage mechanisms do not occur in the absence of portland cement. Therefore, SCM replacement, simply through dilution, has to be taken into account. When the product of calcium hydroxide consumption and SCM replacement is low $(<15$, data points shown in red), the expansion is high and the material is unlikely to mitigate ASR. On such materials, there is no need to perform long and laborious ASR testing. On the other hand, when the product of calcium hydroxide consumption and SCM replacement is high (>35, data points shown in green), the expansion is low, the material is likely to mitigate ASR, and direct ASR testing is desirable. When the product of calcium hydroxide consumption and SCM replacement is moderate (15 to 35 , data points shown in orange), the material may or may not be able to mitigate ASR. In such cases, factors other than reactivity could dominate expansion. Because free alkali, calcium, and alumina contents can strongly influence ASR expansion, developed relationships require corrections based on SCM composition [34,36].

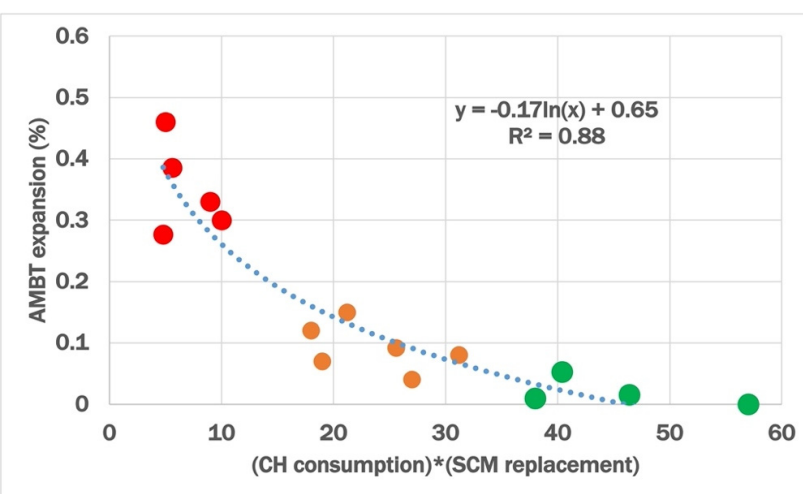

Figure 6. Accelerated mortar bar test expansion at 14-days plotted as a function of SCM calcium hydroxide consumption multiplied by SCM replacement in mortars (unpublished data).

\subsection{The lime strength test}

Kasaniya et al. performed detailed investigations into the links between concrete strength and durability and the mortar lime strength for a number of SCMs [18,34]. The 7-day lime strength provided a reasonable, although not strong indication of 91-day concrete strength $\left(R^{2}=0.56\right)$. Data scatter was evident: in a relatively narrow band of 7-day lime strength (5 to $10 \mathrm{MPa}$; all SCMs classed as moderate reactivity), the 91-day concrete compressive strength varied between $\sim 48$ and $65 \mathrm{MPa}$ [18]. A similar level of correlation was also observed between the 91-day chloride ion migration coefficient and the 7-day lime strength. The scatter is explained by different reaction kinetics, and secondary factors such as chloride binding and pore solution compositional alterations that affect durability apart from microstructural refinement [18]. Sulfate attack and ASR expansion were studied by the authors on the same set of SCMs [34]. No relationship was found between sulfate attack expansion and the lime strength, in part because of two major outliers (Class C fly ash and metakaolin). These SCMs are reactive and developed lime strength but did not mitigate sulfate expansion, highlighting the complexity of concrete durability behavior. As the lime strength increased, ASR expansion reduced. However, mortars high in alkali or $\mathrm{CaO}$ were outliers and had greater expansion than would be expected from their lime strength [34]. The authors emphasized that sulfate attack and ASR expansion depend on reactivity, but also on SCM chemical composition and replacement level in a complex manner. By incorporating corrections based on $\mathrm{SCM} \mathrm{Na}{ }_{2} \mathrm{O}$ and $\mathrm{CaO}$, lime strength was able to better predict ASR expansion [34]. Lime strength, like heat release, is an overall measure of reactivity. Correcting lime strength for $\mathrm{CaO}$ content would make it a measure of pozzolanic reactivity - similar to calcium hydroxide consumption. Therefore, screening of materials for ASR expansion based on (pozzolanic) reactivity is promising.

Not all concrete durability behavior is governed by pozzolanic reactivity and not all concrete needs to be durable. However, reactivity testing shows the ability to rapidly screen inert materials, which will most likely not benefit durability [36]. Laborious and time consuming durability testing is not needed for these materials. As the number of SCM sources is large, reactivity testing could be exploited to quickly identify the most promising sources for further investigation. While reactivity is clearly important for durability, it is far from the only factor that controls concrete durability - SCM chemical composition, SCM replacement level, and other factors are also important $[18,34,36]$. Nevertheless, the findings discussed in this section show that chloride diffusion, calcium oxychloride damage, and ASR expansion are strongly controlled and could be predicted by reactivity, although sulfate attack is not.

\subsection{Bulk resistivity index test}

Later-age bulk resistivity, similar to calcium hydroxide consumption, is largely controlled by pozzolanic reaction induced microstructural densification. Therefore, it correlates with chloride migration coefficient [18], calcium oxychloride damage [38,39], and ASR expansion [41,42]. The bulk resistivity index test involves the measurement of bulk resistivity at $50{ }^{\circ} \mathrm{C}$. We have studied whether 3-day or 7-day bulk resistivity measurements at $50{ }^{\circ} \mathrm{C}$ are representative of 90-day or 180 -day bulk resistivity measurements at $23^{\circ} \mathrm{C}$ [43]. 
A single relationship between these two measurements was not found; the relationship was influenced by SCM composition, reactivity, and especially replacement level. Therefore, similar to calcium hydroxide consumption and lime strength, the bulk resistivity index could also be used to screen for durability after certain corrections are made.

\section{Further thoughts on reactivity}

The four tests described here are commonly run for 7-10 days but reactivity has been quantified at earlier durations, ranging from 0.5 to 3 days $[13,29,44]$. Reaction kinetics in the modified $R^{3}$ test and the potential for reducing test duration were explored in [44]. It was emphasized that only utilizing the reactivity measured at the end of the test may not provide a complete picture of material behavior, which is one concern with the discrete bound water measurement. Reaction kinetics are especially important for slowly reacting materials such as Class F fly ashes and other highly siliceous SCMs. Fig. 7 shows the relationship between 10-day and 3-day heat release for $50+$ SCMs. The strong linear relationship implies that the test duration could be reduced to 3-days and most materials release about $80 \%$ of the 10 -day heat release at 3days. The slowly reacting Class $\mathrm{F}$ fly ashes are outliers; their 3day heat release is around $70 \%$ of their 10 -day heat release. Class F fly ashes react slowly (Fig. 2) when the test duration is short or temperatures are lower, but their reaction is sustained, and at later ages, their contributions to concrete strength and durability surpass those of most SCMs $[3,11,18,21,34]$. Kinetic considerations are important in reactivity tests, and have been somewhat ignored. While test duration can be shortened, this may lead to an incorrect classification of slowly reacting materials.

Regardless of kinetic considerations, all tests are able to successfully screen inert and reactive materials. Heat release/bound water and lime strength, as measures of overall reactivity, show correlations to strength, as discussed in Section 4. Heat release and lime strength can predict ASR expansion when pozzolanic materials are studied but compositional corrections are needed for high $\mathrm{CaO}$ materials $[34,36]$. Calcium hydroxide consumption appears to control calcium oxychloride damage, ASR expansion, and bulk resistivity evolution $[10,19,15,32,38,39]$. An argument could be made that calcium hydroxide consumption is a superior measure of reactivity, but as Fig. 3 shows, it is rather trivial to estimate calcium hydroxide consumption from the heat release in most cases. Heat release and calcium hydroxide consumption require complex and expensive equipment to measure, which may limit the ability of several labs to run such measurements. These labs could potentially measure bound water, and estimate calcium hydroxide consumption from the bound water, if needed. Ultimately, the four reactivity tests provide critical information about SCMs, and it is envisioned that their adoption in specifications will increase $\mathrm{SCM}$ usage and decrease cement $\mathrm{CO}_{2}$ emissions. Their adoption will also prevent the misuse of inert materials, which may be classified as reactive in specifications such as ASTM C618 based on their strength activity index [15]. Therefore, standardizing these tests and using them in specifications to replace flawed tests such as the strength activity test [15] is a worthwhile endeavor. Developing an online material reactivity database that provides physicochemical characterization and reactivity of different materials could assist in ultimately increasing utilization of novel SCMs. Reactivity test outputs could be used as inputs in modeling; doing so through carefully validated models can allow for the prediction of concrete strength and durability properties with minimal experimental effort [45-47]. Physical, chemical, mechanical, and thermal processing/modification of SCMs is becoming increasingly common and reactivity tests can provide mechanistic insights into how such processing affects SCM behavior [33,48-50].

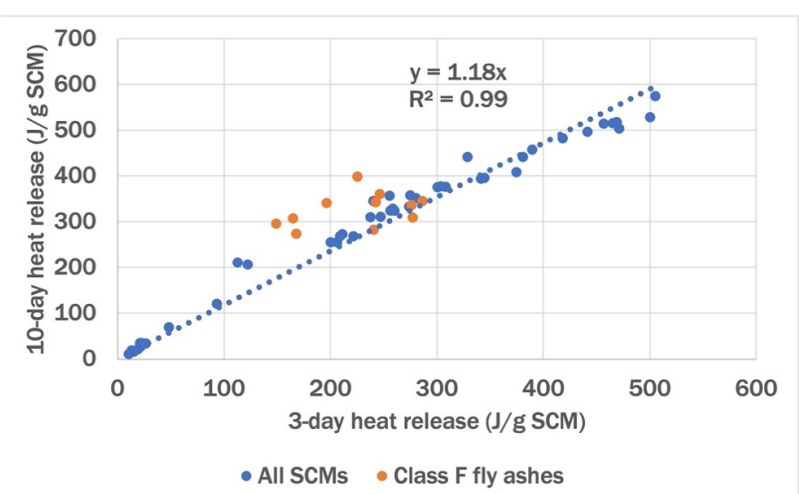

Figure 7. Relationship between 10-day and 3-day heat release in the modified $\mathrm{R}^{3}$ test (adapted from [44]).

\section{Conclusions}

Four recently developed reactivity tests - the $R^{3}$ test (ASTM C1897), the modified $R^{3}$ test, the lime strength test, and the bulk resistivity index test are discussed. All tests screen inert and reactive materials and are promising for standards and specifications replacing currently existing methods. The reactivity test outputs, heat release, bound water, calcium hydroxide consumption, strength, and bulk resistivity are strongly correlated, however, heat release, bound water, and strength measure overall reactivity. In order to estimate pozzolanic reactivity or to differentiate pozzolanic and latent hydraulic materials, calcium hydroxide consumption and heat release (or a compositional correction), are needed. SCM bulk chemistry, amorphous content, and fineness have complex influences on SCM reactivity, but studies on synthetic SCM systems show that reactivity is overwhelmingly controlled by structural disorder/depolymerization/destabilization. Heat release, bound water, and lime strength can be used to estimate concrete strength, but durability assessments are more complex. Calcium hydroxide consumption is able to predict some durability behavior, but not others, and corrections for oxide composition and crystalline phases might be required to improve the obtained correlations. Rapid reactivity information which could be used to screen for durability may be obtained in as little as 0.5 days, however, caution must be exercised for slowly reacting SCMs.

\section{Acknowledgements}

The author would like to Dr. Luis Ruiz Pestana, Dr. Sivakumar Ramanathan, and Ms. Ying Wang for insightful discussions. 
The PhD research of Dr. Ramanathan and Ms. Wang forms a considerable portion of the presented results. Support from the National Science Foundation (CMMI-2101961), Knight Foundation Endowment in the College of Engineering (University of Miami), and the Department of Civil and Architectural Engineering (University of Miami) is gratefully acknowledged. The 2021 RILEM Gustavo Colonnetti Award awarded to Dr. Prannoy Suraneni made possible the submission of this manuscript.

\section{Authorship statement (CRediT)}

Prannoy Suraneni: Conceptualization, Supervision, Resources, Writing - review and editing, Project administration, Funding acquisition.

\section{References}

[1] K.L. Scrivener, V.M. John, E.M. Gartner, Eco-efficient cements: Potential economically viable solutions for a low- $\mathrm{CO}_{2}$ cement-based materials industry. Cem Concr Res (2018) 114: 2-26. https://doi.org/10.1016/i.cemconres.2018.03.015

[2] A. Hasanbeigi, L. Price, E. Lin, Emerging energy-efficiency and $\mathrm{CO} 2$ emission-reduction technologies for cement and concrete production: A technical review, Renew Sust Energ Rev (2012) 16: 6220-6238. https://doi.org/10.1016/i.rser.2012.07.019

[3] M.C.G. Juenger, R. Snellings, S.A. Bernal, Supplementary cementitious materials: New sources, characterization, and performance insights, Cem Concr Res (2019) 122: 257-273. https://doi.org/10.1016/j.cemconres.2019.05.008

[4] M.H. Shehata, M.D.A. Thomas, The effect of fly ash composition on the expansion of concrete due to alkali-silica reaction, Cem Concr Res (2000) 30: 1063-1072. https://doi.org/10.1016/S0008-8846(00)00283-0

[5] M.M.A. Elahi, et. al., Improving the sulfate attack resistance of concrete by using supplementary cementitious materials (SCMs): A review, Constr Build Mater (2021) 281: 122628. https://doi.org/10.1016/j.conbuildmat.2021.122628

[6] G. Kaladharan, A. Gholizadeh-Vayghan, F. Rajabipour, Review, sampling, and evaluation of landfilled fly ash, ACI Mater J (2019) 116: 113-122. https://doi.org/10.14359/51716750

[7] I. Diaz-Loya, M.C.G. Juenger, S. Seraj, R. Minkara, Extending supplementary cementitious material resources: Reclaimed and remediated fly ash and natural pozzolans, Cem Concr Compos (2019) 101: 44-51. https://doi.org/10.1016/i.cemconcomp.2017.06.011

[8] F. Avet, R. Snellings, A.A. Diaz, M.B. Haha, K. Scrivener, Development of a new rapid, relevant and reliable (R3) test method to evaluate the pozzolanic reactivity of calcined kaolinitic clays, Cem Concr Res (2016) 85: 1-11. https://doi.org/10.1016/i.cemconres.2016.02.015

[9] P. Suraneni, A. Hajibabaee, S. Ramanathan, Y. Wang, J. Weiss, New insights from reactivity testing of supplementary cementitious materials, Cem Concr Compos (2019) 103: 331-338. https://doi.org/10.1016/i.cemconcomp.2019.05.017

[10] S. Ramanathan, M. Croly, P. Suraneni, Comparison of the effects that supplementary cementitious materials replacement levels have on cementitious paste properties, Cem Concr Compos (2020) 112: 103678. https://doi.org/10.1016/j.cemconcomp.2020.103678

[11] M.C.G Juenger, R. Siddique, Recent advances in understanding the role of supplementary cementitious materials in concrete, Cem Con Res (2015) 78: 71-80. https://doi.org/10.1016/j.mineng.2019.106026

[12] R. Snellings, K.L. Scrivener, Rapid screening tests for supplementary cementitious materials: Past and future, Mater Struct (2015) 49: 3265-3279. https://doi.org/10.1617/s11527-015-0718-z

[13] X. Li, et al., Reactivity tests for supplementary cementitious materials: RILEM TC 267-TRM phase 1, Mater Struct (2018) 51: 1-14. https://doi.org/10.1617/s11527-018-1269-x

[14] M. Kasaniya, M.D.A. Thomas, E.G. Moffatt, Development of rapid and reliable pozzolanic reactivity test method, ACI Mater J (2019) 116: 145-154. https://doi.org/10.14359/51716718

[15] Y. Wang, L. Burris, C.R. Shearer, D. Hooton, P. Suraneni, Strength activity index and bulk resistivity index modifications that differentiate inert and reactive materials, Cem Concr Compos (2021) 124: 104240. https://doi.org/10.1016/j.cemconcomp.2021.104240
[16] R. Snellings, X. Li, F. Avet, K. Scrivener, Rapid, robust, and relevant $\left(R^{3}\right)$ reactivity test for supplementary cementitious materials, ACI Mater J (2019) 116: 155-162. https://doi.org/10.14359/51716719

[17] P. Suraneni, J. Weiss, Examining the pozzolanicity of supplementary cementitious materials using isothermal calorimetry and thermogravimetric analysis, Cem Concr Compos (2017) 83: 273-278. https://doi.org/10.1016/j.cemconcomp.2017.07.009

[18] M. Kasaniya, M.D.A. Thomas, E.G. Moffatt, Pozzolanic reactivity of natural pozzolans, ground glasses and coal bottom ashes and implication of their incorporation on the chloride permeability of concrete, Cem Concr Res (2021) 139: 106259. https://doi.org/10.1016/j.cemconres.2020.106259

[19] S. Ramanathan, M. Kasaniya, M. Tuen, M.D.A. Thomas, P. Suraneni, Linking reactivity test outputs to properties of cementitious pastes made with supplementary cementitious materials, Cem Concr Compos (2020) 114: 103742. https://doi.org/10.1016/i.cemconcomp.2020.103742

[20] M. Shakouri, C.L. Exstrom, S. Ramanathan, P. Suraneni, J.S. Vaux, Pretreatment of corn stover ash to improve its effectiveness as a supplementary cementitious material in concrete, Cem Concr Compos (2020) 112: 103658 . https://doi.org/10.1016/j.cemconcomp.2020.103658

[21] Y. Wang, L. Burris, R.D. Hooton, C.R. Shearer, P. Suraneni, Effects of unconventional fly ashes on cementitious paste properties, Cem Concr Compos (2022) 125: 104291 https://doi.org/10.1016/j.cemconcomp.2021.104291

[22] K. Weise, N. Ukrainczyk, E. Koenders, A mass balance approach for thermogravimetric analysis in pozzolanic reactivity R3 test and effect of drying methods, Materials (2021) 14: 5859. https://doi.org/10.3390/ma14195859

[23] A. Schöler, F. Winnefeld, M.B. Haha, B. Lothenbach, The effect of glass composition on the reactivity of synthetic glasses, J Am Ceram Soc (2017) 100: 2553-2567. https://doi.org/10.1111/jace.14759

[24] S. Kucharczyk, Structure and reactivity of synthetic $\mathrm{CaO}-\mathrm{Al}_{2} \mathrm{O}_{3}-\mathrm{SiO}_{2}$ glasses, Cem Concr Res (2019) 120: 77-91. https://doi.org/10.1016/j.cemconres.2019.03.004

[25] S. Nie, R.N. Thomsen, J. Skibsted, Impact of Mg substitution on the structure and pozzolanic reactivity of calcium aluminosilicate $(\mathrm{CaO}-$ $\mathrm{Al}_{2} \mathrm{O}_{3}-\mathrm{SiO}_{2}$ ) glasses, Cem Concr Res (2020) 138: 106231. https://doi.org/10.1016/i.cemconres.2020.106231

[26] S. Blotevogel, et al., Effect of $\mathrm{TiO} 2$ and 11 minor elements on the reactivity of ground granulated blast-furnace slag in blended cements, J Am Ceram Soc (2021) 104: 128-139. https://doi.org/10.1111/jace.17431

[27] M. Maier, N. Beuntner, K.-C. Thienel, Mineralogical characterization and reactivity test of common clays suitable as supplementary cementitious material, Appl Clay Sci (2021) 202: 105990. https://doi.org/10.1016/i.clay.2021.105990

[28] R. Fernandez, F. Martirena, K.L. Scrivener, The origin of the pozzolanic activity of calcined clay minerals: A comparison between kaolinite, illite and montmorillonite, Cem Concr Res (2011) 41: 113-122. https://doi.org/10.1016/i.cemconres.2010.09.013

[29] S. Blotevogel, et al., Ability of the R3 test to evaluate differences in early age reactivity of 16 industrial ground granulated blast furnace slags (GGBS), Cem Concr Res (2020) 130: 105998. https://doi.org/10.1016/j.cemconres.2020.105998

[30] V. Hallet, N. De Belie, Y. Pontikes, The impact of slag fineness on the reactivity of blended cements with high-volume non-ferrous metallurgy slag, Constr Build Mater (2020) 257: 119400. https://doi.org/10.1016/j.conbuildmat.2020.119400

[31] S. Ramanathan, P. Perumal, M. Illikainen, P. Suraneni, Mechanically activated mine tailings for use as supplementary cementitious materials, RILEM Tech Lett (2021) 6: 61-69. https://doi.org/10.21809/rilemtechlett.2021.143

[32] S. Ramanathan, M. Tuen, P. Suraneni, Influence of supplementary cementitious material fineness on their reactivity in model systems and cementitious pastes, Mater Struct (2021) under review.

[33] R. Snellings, H. Kazemi-Kamyab, P. Nielsen, L. Van den Abeel, Classification and milling increase fly ash pozzolanic reactivity, Front Built Environ (2021) 7: 670996. https://doi.org/10.3389/fbuil.2021.670996

[34] M. Kasaniya, M.D.A. Thomas, E.G. Moffatt, Efficiency of natural pozzolans, ground glasses and coal bottom ashes in mitigating sulfate attack and alkali-silica reaction, Cem Concr Res (2021) 149: 106551. https://doi.org/10.1016/i.cemconres.2021.106551 
[35] H.A. Ali, D. Xuan, C.S. Poon, Assessment of long-term reactivity of initially lowly-reactive solid wastes as supplementary cementitious materials (SCMs), Constr Build Mater (2020) 232: 117192. https://doi.org/10.1016/j.conbuildmat.2019.117192

[36] S. Al-Shmaisani, Assessing supplementary cementitious materials for use in concrete: long-term and rapid testing, $\mathrm{PhD}$ dissertation, University of Texas at Austin (2020).

[37] P. Suraneni, V.J. Azad, O.B. Isgor, J. Weiss, Role of supplementary cementitious material type in the mitigation of calcium oxychloride formation in cementitious pastes, J Mater Civ Eng (2018) 30: 04018248. https://10.1061/(ASCE)MT.1943-5533.0002425

[38] C. Qiao, P. Suraneni, J. Weiss, Flexural strength reduction of cement pastes exposed to $\mathrm{CaCl} 2$ solutions, Cem Concr Compos (2018) 86: 297-305. https://doi.org/10.1016/j.cemconcomp.2017.11.021

[39] N. Hosseinzadeh, L. Montanari, P. Suraneni, Durability of concretes exposed to high concentrations of $\mathrm{CaCl}_{2}$ and $\mathrm{MgCl}_{2}$, Mater Struct (2021) under review.

[40] H. Layssi, P. Ghods, A.R. Alizadeh, M. Salehi, Electrical resistivity of concrete, Concr Int (2015) 37: 41-46.

[41] K.S.T. Chopperla, J.H. Ideker, Using electrical resistivity to determine the efficiency of supplementary cementitious materials to prevent alkali-silica reaction in concrete, Cem Concr Compos (2022) 125: 104282. https://doi.org/10.1016/i.cemconcomp.2021.104282

[42] K.S.T Chopperla, et al., Combining reliable performance testing and binder properties to determine preventive measures for alkali-silica reaction, Cem Concr Res (2022) 151: 1066441. https://doi.org/10.1016/j.cemconres.2021.106641

[43] N. Hosseinzadeh, Effects of air content and supplementary cementitious materials in reducing damage in concrete exposed to high concentrations of deicing salt and various temperature conditions, PhD dissertation, University of Miami (2021).

[44] S. Ramanathan, Reactivity of supplementary cementitious materials in model systems and cementitious pastes, PhD dissertation, University of Miami (2021).

[45] K. Bharadwaj, R.M. Ghantous, F. Sahan, O.B. Isgor, W.J. Weiss, Predicting pore volume, compressive strength, pore connectivity, and formation factor in cementitious pastes containing fly ash, Cem Concr Compos (2021) 122: 104113.

https://doi.org/10.1016/j.cemconcomp.2021.104113

[46] D. Glosser, P. Suraneni, O.B. Isgor, W.J. Weiss, Using glass content to determine the reactivity of fly ash for thermodynamic calculations, Cem Concr Compos (2021) 115: 103849. https://doi.org/10.1016/j.cemconcomp.2020.103849

[47] K. Bharadwaj, D. Glosser, M.K. Moradllo, O.B. Isgor, W.J. Weiss, Toward the prediction of pore volumes and freeze-thaw performance of concrete using thermodynamic modelling, Cem Concr Res (2019) 124: 105820. https://doi.org/10.1016/i.cemconres.2019.105820

[48] F. Zunino, K. Scrivener, Increasing the kaolinite content of raw clays using particle classification techniques for use as supplementary cementitious materials, Constr Build Mater (2020) 244: 118335. https://doi.org/10.1016/i.conbuildmat.2020.118335

[49] K. Jafari, F. Rajabipour, Performance of impure calcined clay as a pozzolan in concrete, Transp Res Rec (2021) 2675: 98-107. https://doi.org/10.1177/0361198120953140

[50] G. Innocenti, D.J. Benkeser, J.E. Dase, X. Wirth, C. Sievers, K.E. Kurtis, Beneficiation of ponded coal ash through chemi-mechanical grinding, Fuel (2021) 299: 120892. https://doi.org/10.1016/j.fuel.2021.120892 